\title{
Rehabilitation program for traumatic chronic cervical pain associated with unsteadiness: a single case study Danik Lafond*1, Annick Champagne ${ }^{1}$, Rosalie Cadieux ${ }^{1}$ and Martin Descarreaux ${ }^{2}$
}

\author{
Address: ${ }^{1}$ Département des sciences de l'activité physique, Université du Québec à Trois-Rivières, Trois-Rivières, Quebec, Canada and \\ ${ }^{2}$ Département de chiropratique, Université du Québec à Trois-Rivières, Trois-Rivières, Quebec, Canada \\ Email: Danik Lafond* - danik.lafond@uqtr.ca; Annick Champagne - annick.champagne@uqtr.ca; Rosalie Cadieux - rosalie.cadieux@uqtr.ca; \\ Martin Descarreaux - martin.descarreaux@uqtr.ca \\ * Corresponding author
}

Published: 17 November 2008

Chiropractic \& Osteopathy 2008, 16:15 doi:10.1186/1746-1340-16-15

This article is available from: http://www.chiroandosteo.com/content//6/1/15

(c) 2008 Lafond et al; licensee BioMed Central Ltd.

This is an Open Access article distributed under the terms of the Creative Commons Attribution License (http://creativecommons.org/licenses/by/2.0), which permits unrestricted use, distribution, and reproduction in any medium, provided the original work is properly cited.
Received: 25 June 2008

Accepted: 17 November 2008

\begin{abstract}
Background: Neck problems are often recurring or chronic. After pain, unsteadiness and balance problems are among the most frequent symptoms reported by chronic neck pain (CNP) patients. Altered sensorimotor control of the cervical spine and sensorimotor integration problems affecting postural control have been observed in CNP patients. Very few data are available regarding the post-intervention effects of rehabilitation programs on postural control in CNP.
\end{abstract}

Case presentation: This is a case study of a traumatic CNP patient (a 45-year old female) with postural unsteadiness who participated in an 8-week rehabilitation program combining therapeutic exercises with spinal manipulative therapy. Pre-intervention data revealed that the postural control system was challenged when postural control sensory inputs were altered, particularly during the head-extended-backward condition. Post-intervention centre of pressure measurements indicated a drastic reduction in postural sway during trials with changes in neck orientation.

Conclusion: This case report indicates that an 8-week rehabilitation program combining therapeutic exercises with spinal manipulative therapy may have had an effect on improvement of postural control in a trauma CNP patient with unsteadiness. These results warrant further studies to investigate the relationships between pain amelioration, sensorimotor control of the cervical spine, muscle fitness and postural steadiness.

\section{Background}

Neck disorders are among the most common and costly health complaints in industrial countries. Lifetime neck pain prevalence is $66 \%$ [1], and recurrent pain or episodes lasting more than 6 months have been reported in $14 \%$ of the adult population [2]. After pain, unsteadiness and balance problems are among the most frequent symptoms encountered by chronic neck pain (CNP) patients [3]. For instance, quantitative posturography studies have discerned increased postural sway in CNP compared to healthy subjects [4-6].

Postural steadiness and balance involve proprioceptive, vestibular and visual postural control subsystems. Cervical proprioceptive afferences play an important role in postural control by providing information regarding head 
position and displacements relative to the trunk [7]. Previous work has shown that modifying neck position challenges the postural control system, in both healthy and CNP subjects [8-10]. Kogler et al. [9] found that changes in neck position elicited more postural sway in neck pain subjects with vertigo compared to healthy controls. Neck muscle afferents enable the central nervous system to locate the head's orientation relative to the trunk and are linked to the vestibular system $[11,12]$. It is hypothesized that postural unsteadiness in CNP could result from a mismatch between modified neck proprioceptive afferences and normal vestibular afferences [4-6]. Altered sensorimotor control of the cervical spine has also been observed in CNP patients with increased neck joint repositioning errors [13-15]. In CNP cases, such disturbances are believed to be a consequence of aberrant cervical proprioceptive inputs or changes in sensorimotor integration. Modulated cervical sensorimotor control in neck pain is thought to occur via several mechanisms, including variations in fusimotor drive impacting muscle spindle sensitivity and modifying cortical representation of cervical afferent input [16-18] as a result of pain, muscle dysfunction and inflammation. Afferences from both labyrinth and neck muscle spindles converge to vestibular nuclei and evoke adaptive postural responses with head movement control strategies [11,12]. Gdowski and McCrea [19] have demonstrated that neck proprioceptive afferences contribute to the shaping of vestibular nucleus outputs, endowing postural steadiness. As a consequence of cervical muscle pain, impaired proprioceptive afferences could elicit mismatching between neck proprioceptive afferences and those from the normal vestibular system, resulting in sensorimotor integration disturbances affecting postural control, as observed in CNP patients. Armstrong et al. [20] pointed out that articular receptors of the cervical spine may complement muscle spindles in the position sense, and damage in mechanoreceptors of the cervical spine could contribute to the pathomechanism of neck pain. Muscle inhibition, muscle atrophy and increased muscle fatigability could also contribute to sensorimotor disturbances in CNP $[21,22]$. These factors seem to support the value of strengthening exercises such as therapeutic rehabilitation in neck pain patients.

The management of cervical sensorimotor control impairments associated with CNP may include strategies, such as exercises aimed at improving cervical proprioception and decreasing neck pain and disability. Therapy involving stretching or strengthening exercises could reduce pain and improve function in CNP, even though the evidence is still limited $[23,24]$. Recently, Jull et al. [25] found that proprioceptive exercises induced greater changes in the joint position sense than cranio-cervical flexion-based exercises. Treleaven $[13,26]$ proposed a multimodal approach, including conventional physiotherapy as well as tailored oculomotor, proprioceptive and balance exercises to retrain sensorimotor control in CNP patients. On the other hand, manipulation when combined with exercises is more effective than manipulation alone in the treatment of neck pain [27-29].

To date, very few data are available regarding the postintervention effects of rehabilitation programs on postural control in CNP patients with associated unsteadiness. The current paper represents a case study of traumatic CNP in a patient who participated in an 8-week exercise therapy program designed to retrain the neck/ shoulder muscles and sensorimotor control of the neck. The rehabilitation program chosen combined exercise with spinal manipulative therapy. This study emphasizes the effect of intervention on postural steadiness.

\section{Case presentation History}

Ms. X, a 45-year-old elementary school music teacher, reported that she had a traumatic neck and dorsal spine injury 2 years ago. It was diagnosed as cervicalgia and dorsalgia. She got up from a squatting position and hit her head under a steel box fixed on a wall 3 feet from the ground. She felt immediate bilateral neck, dorsal and lumbar pain and stiffness, and also reported blurred vision and nausea. The next day, she visited her physician where cervical, dorsal and lumbar X-rays were taken. No particular lesion could be identified by X-rays. Six months later, she was scheduled for CT and bone scans of the cervico-thoracic spine that once again did not lead to any specific diagnosis with the exception of moderate degenerative disc disease at T8 and T9. Her cervico-thoracic spine pain had persisted since then, accompanied by pain radiating to the right shoulder. The patient also reported moderate restriction of her cervical range of motion and intermittent occipital headache, particularly when neck pain was exacerbated. Her symptoms were increased by sustained neck positions, computer work for several minutes and sitting in a car for prolonged periods as driver or passenger. She also reported insomnia as a result of neck pain. She was off work for 15 months after the injury and returned to work progressively in the last 18 months, on a part-time basis. The patient received physical therapy during the first 18 months after her injury. Before consulting for exercise therapy, she received chiropractic treatments (mainly spinal manipulative therapy), twice a week for 3 months, to restore mobility of the cervical and dorsal spine. At that time, and based on the absence of any neurological signs, the patient was diagnosed as having "mechanical neck pain". Chiropractic treatments temporarily relieved her symptoms, but the pain and stiffness kept returning 48-72 $\mathrm{h}$ after spinal manipulative therapy. At the time of the first consultation in kinesiology (exercise therapy), moderate limitation in cervical range of 
motion was observed, with stiffness and tightness of the right upper trapezius muscle and bilateral trigger points in the medial scapular region. The patient reported baseline neck pain of $6 / 10$ on the visual analogue scale (VAS) at the beginning of the intervention. She took non-steroidal anti-inflammatory drugs 2-3 times a week. She had no past history of neck pain and unsteadiness prior to the traumatic incident.

\section{Postural stability assessment}

Sensorimotor control was assessed by posturography analysis a few days before and after the 8-week intervention program. Postural steadiness was measured on a force plate (OR6-2000, AMTI, Watertown, MA, USA). The patient was asked to stand barefoot on the force plate, with her feet in a narrow stance (feet side-by-side position), arms hanging at her sides and her head in a normal, forward-looking position. Outlines of her feet were traced to ensure that foot placement was constant across trials. Each trial lasted $30 \mathrm{~s}$. A modified version of the Clinical Test of Sensory Interaction on Balance (mCTSIB) was used [30] to assess the relative contributions of 3 sensory inputs of the postural control system. In this case study, the mCTSIB involved 10 quiet standing trials (see Table 1 ), with a varying surface (firm and soft support) and visual input (eyes-open (EO) and eyes-closed (EC)). To reduce the contribution of the vestibular system or to exacerbate the mismatch between vestibular and neck proprioceptive inputs, 3 additional head positions were tested. The 3 neck positions were: maximum neck/head extension backward (EXT) and maximum lateral flexion of the neck to the right (RLF) and left sides (LLF). No trunk movement was allowed during the neck displacements. At the beginning of each trial, the patient was asked to perform neck movements within a comfortable limit and to maintain the position during the 30-s trial.

Ground reaction forces and moments were recorded from the force platform. Analog signals were sampled at a fre-

Table I: Testing conditions during the modified Clinical Test of Sensory Interaction on Balance (mCTSIB)

\begin{tabular}{cccc}
\hline Conditions & Vision & Surface* & Neck movements \\
\hline 1 & Eyes open & Firm & Head neutral \\
2 & Eyes open & Soft & Head neutral \\
3 & Eyes open & Soft & Left lateral flexion \\
4 & Eyes open & Soft & Right lateral flexion \\
5 & Eyes open & Soft & Extension \\
6 & Eyes closed & Firm & Head neutral \\
7 & Eyes closed & Soft & Head neutral \\
8 & Eyes closed & Soft & Left lateral flexion \\
9 & Eyes closed & Soft & Right lateral flexion \\
10 & Eyes closed & Soft & Extension
\end{tabular}

* Soft surface: a 10-cm thick layer of polyethylene foam placed on top of the platform. quency of $100 \mathrm{~Hz}$ and filtered with a zero-lag sixth-order Butterworth low-pass filter at $6 \mathrm{~Hz}$ of cut-off frequency. Details of data processing are reported elsewhere [31]. Mean centre of pressure (COP) speed (mm/s) and sway area $\left(\mathrm{mm}^{2}\right)$ were calculated to characterize postural steadiness. COP speed was defined as total COP displacement divided by the total period. Minimal metrically-detectable changes (MMDC) for COP speed in both the antero-lateral $(\mathrm{A} / \mathrm{L})$ and medio-lateral $(\mathrm{M} / \mathrm{L})$ directions and COP sway area were calculated by the intra-class coefficient and standard deviation (SD) reported earlier [32]. For a 30-s trial in the EO and firm surface condition, the MMDC of COP speed were $\pm 1.73 \mathrm{~mm} / \mathrm{s}$ and $\pm 0.71 \mathrm{~mm} / \mathrm{s}$ in the A/ $\mathrm{L}$ and $\mathrm{M} / \mathrm{L}$ directions, respectively, and $\pm 80.1 \mathrm{~mm}^{2}$ for COP sway area. These values served to detect clinically-significant changes in postural steadiness after the intervention. To the authors' knowledge, intra- and inter-session reliability and MMDC in COP measurements have never been tested in neck pain subjects.

\section{Exercise therapy}

After the initial evaluation (18 months post-injury), the subject performed exercise training twice a week for 8 weeks. Each session, lasting $60 \mathrm{~min}$, was supervised by an experienced kinesiologist. The exercise therapy program was aimed at improving neck muscle fitness and sensorimotor control of the cervical spine. It included:

- Strengthening exercises: with the head positioned against gravity to enhance isometric strength of the neck extensor muscles. Typical strengthening exercises for the paraspinal muscles and shoulder girdle muscles (upper and middle trapezius, rhomboids) are illustrated in Figure 1. These exercises were designed to increase sustained isometric effort tolerance of the neck muscles. Progression included unstable surface and escalating resistance.

- Oculomotor and head/eye exercises: in the upright, sitting and supine positions. Eye tracking involved moving target exercises (Figure 2A) and eye/head coordination exercises (Figure 2B). Progression included increasing neck rotation amplitude, instability on a Swiss ball and augmenting neck muscle activity with the head in a weightdependent position (Figure 2C).

- Balancing exercises: standing with a narrow stance, tandem stance and single leg stance. Progression included the use of foam under each foot to augment postural instability (Figure 3). Visual inputs were manipulated by focusing on a point $2 \mathrm{~m}$ away on the wall at eye level and under EO plus EC conditions. These exercises typically lasted $30 \mathrm{~s}$.

- Stretching exercises: to sometimes reduce neck/shoulder stiffness and enhance neck range of motion. 

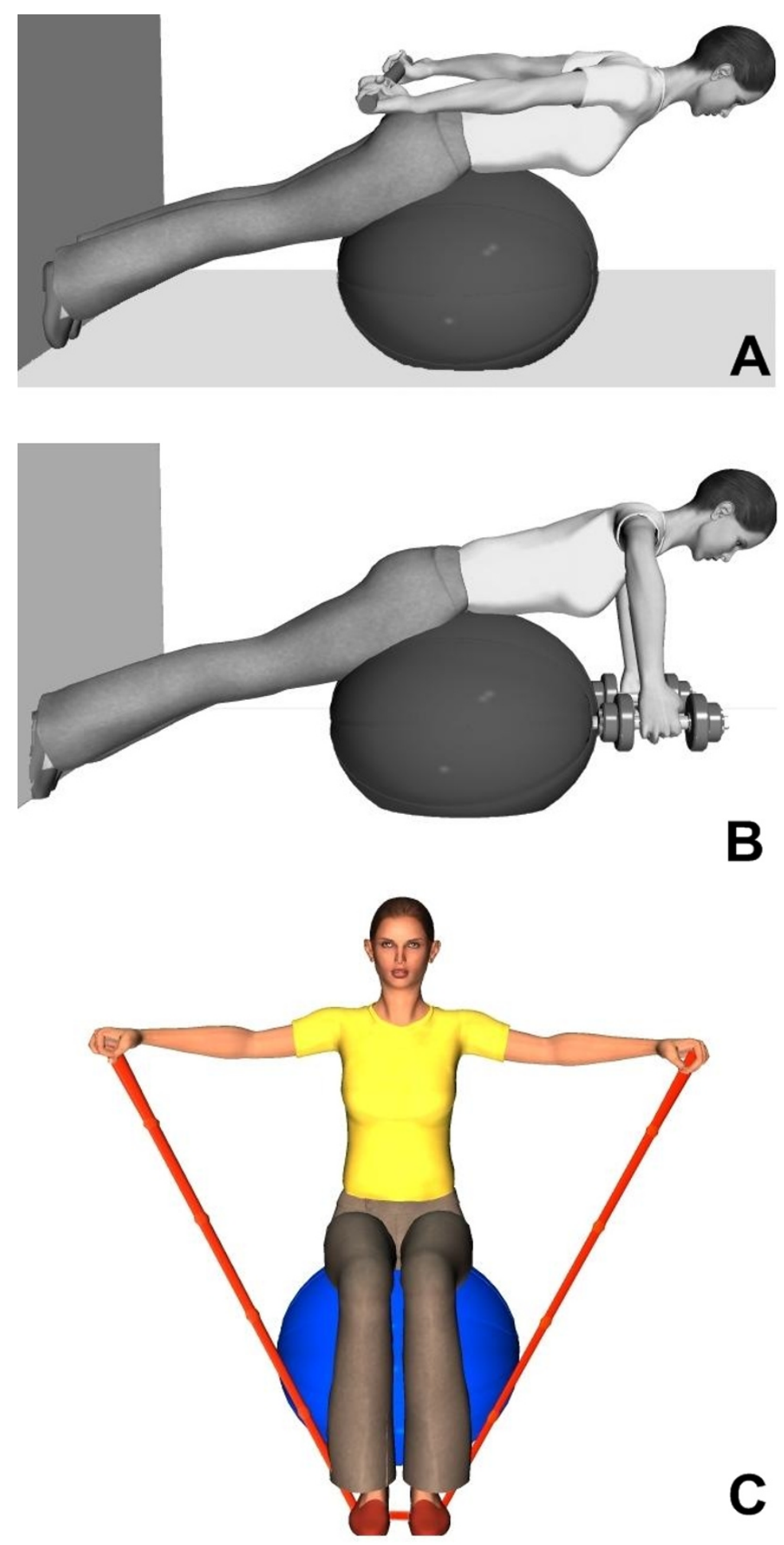

\section{Figure I}

Example of paraspinal, neck and shoulder girdle muscle-strengthening exercises. A) Sorenson type exercise with isometric contraction to keep the shoulder in extension and the scapulas in adduction. B) Sorenson type exercise with thighs and hips supported on a Swiss ball. Isometric paraspinal contraction combining adduction/abduction of the scapulas. C) Isometric lateral shoulder raises with elastic resistance. The exercise could be performed sitting on a stable surface (e.g. a chair) or on a Swiss ball. 

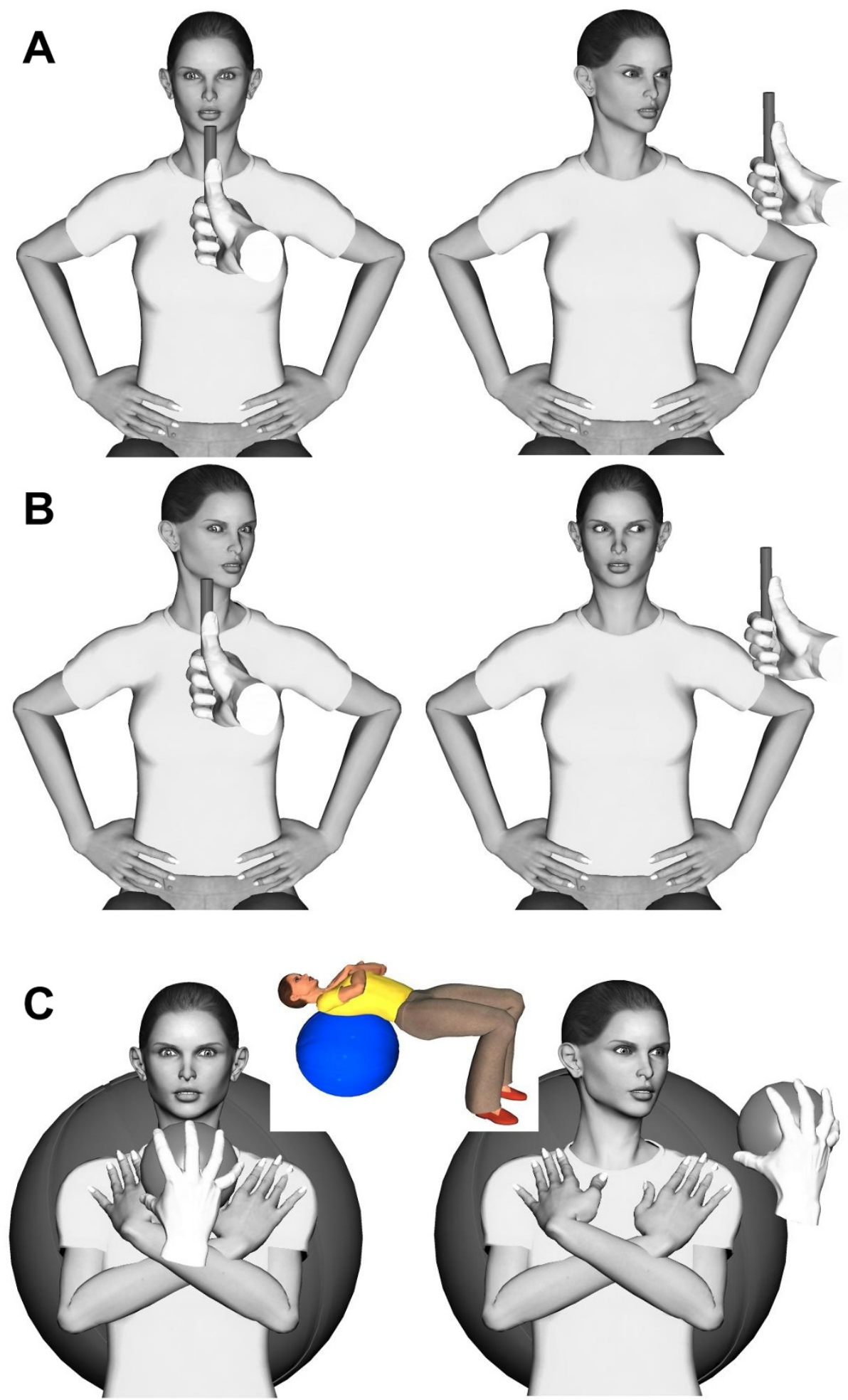

Figure 2

Oculomotor and head/eye proprioceptive exercises. A) Head-to-target or head movement following the target with the eyes in a neutral position. B) Eyes-to-target or eye movement following the target with different head positions. C) Headto-target or head movement following the target with the eyes in a neutral position and the subject lying supine on a Swiss ball, with the head in a weight-dependent neutral position. 

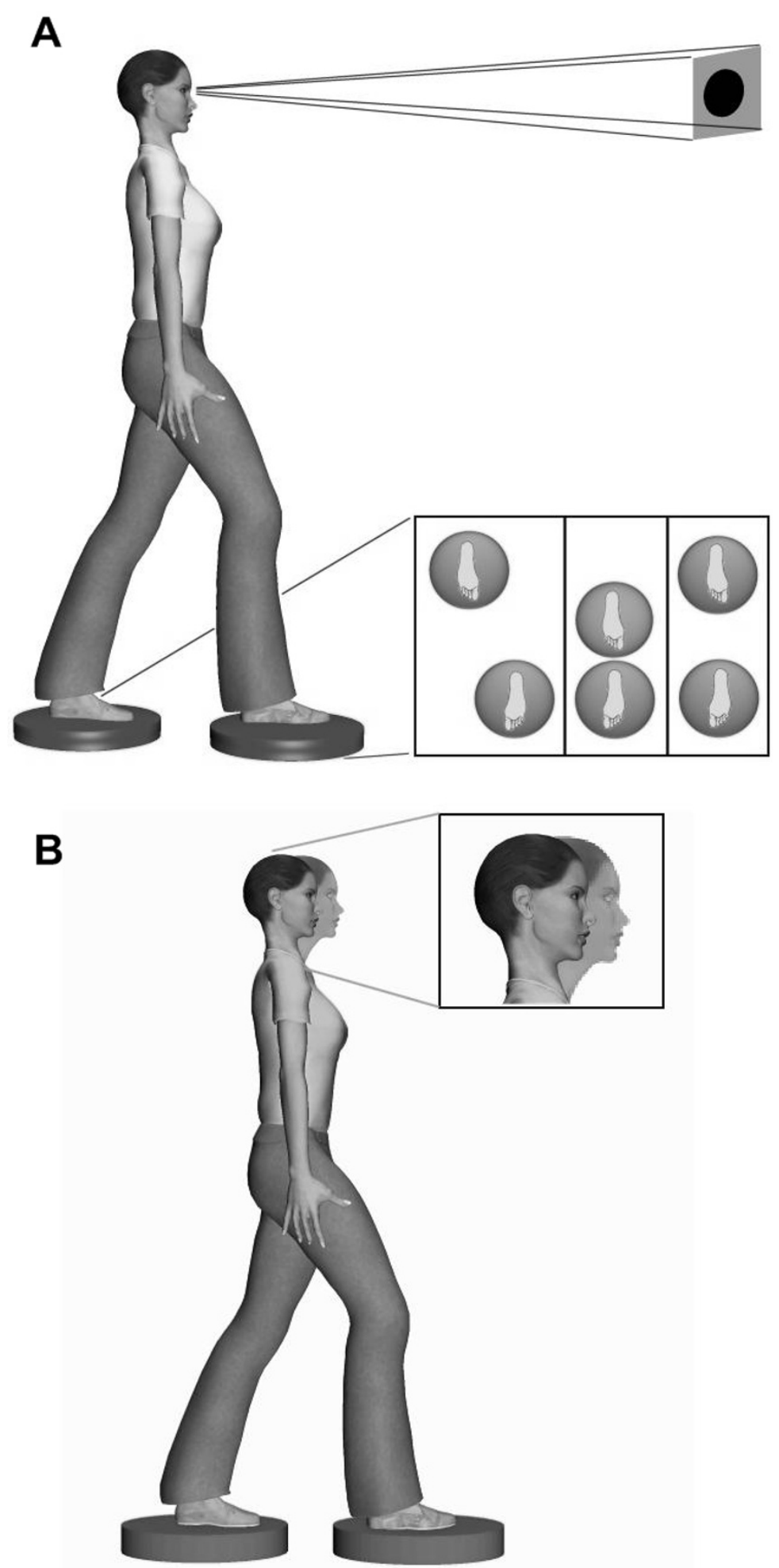

\section{Figure 3}

Gaze stabilization and postural stability exercises. A) Fixing a target during a challenging postural stability task. Feet in tandem positions increase postural constraints. B) Fixing a target during a challenging postural stability task combining movements of the neck/head. 


\section{Spinal manipulative therapy}

After ruling out all risk factors for major adverse events (vertebral artery dissection or the presence of major vertebral pathologies), the chiropractor initiated a series of treatments. Twice a week during the 8-week program, spinal manipulative therapy was applied to the patient's spine. The mobilization techniques and manipulated joints were chosen according to chiropractor clinical assessment that included the patient's history, physical examination as well as joint and muscle palpation. Treatment consisted of short-amplitude, high-velocity spinal manipulative thrust (chiropractic-diversified technique) on vertebral segments determined by manual palpation of joint restrictions and tenderness. Since pain on palpation was identified at the C2-C3 level on both sides, chiropractic adjustments were performed at this level either left or right, depending on the patient's pain tolerance.

\section{Effects of the rehabilitation program}

Pain was the only clinical outcome formally monitored before and after the rehabilitation program. Prior to the program the patient reported significant pain and scored $6 / 10$ on the VAS. Following the 8 week rehabilitation program, the patient scored 2/10 on the VAS. Associated neck
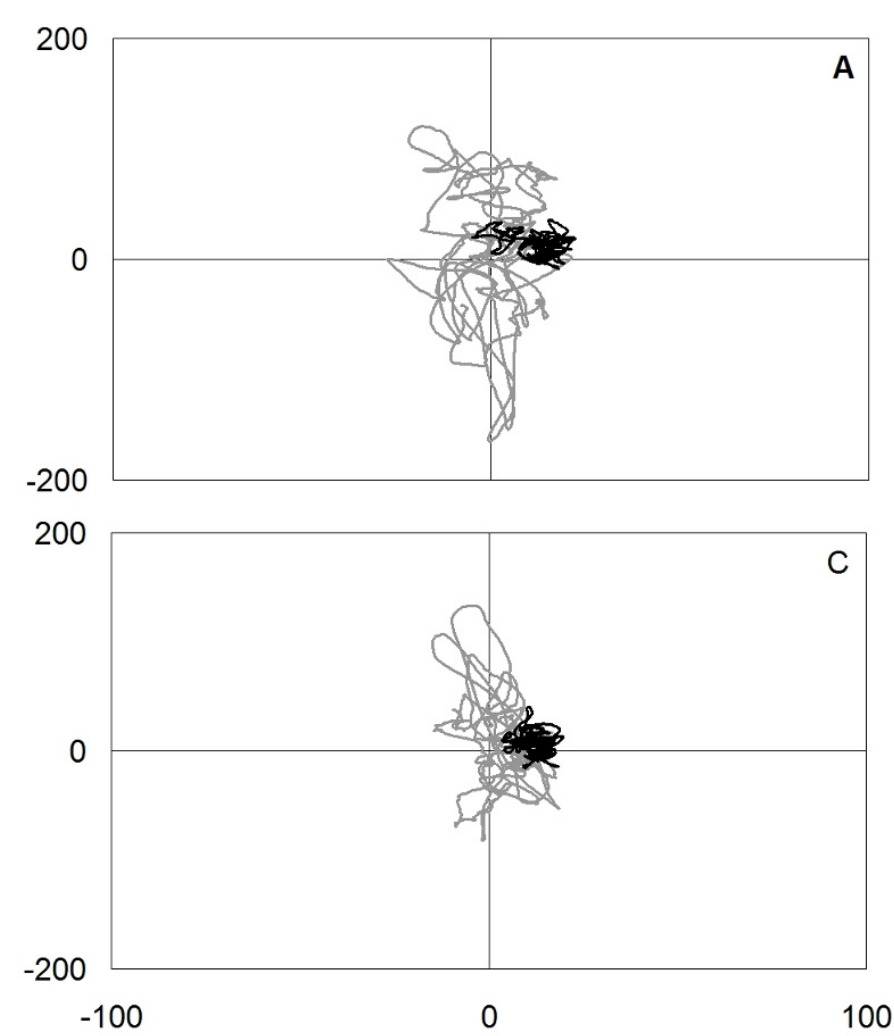

disabilities were not assessed during the treatment period but the patient returned to work fulltime after a 24-month sick leave related to neck pain and disabilities. It was decided that the patient was able to return to usual working activities following what was described by the patient as a significant improvement in neck pain and related disabilities.

Pre- and post-intervention COP measures are shown in Figures 4 and 5. After 16 exercise sessions, the COP sway area decreased between $74.7 \%$ (EO, foam surface, LLF) and $95.4 \%$ (EC, foam surface, RLF). However, in condition 1 (EO, firm surface), the COP sway area increased from $86 \mathrm{~mm}^{2}$ to $100.3 \mathrm{~mm}^{2}(14.7 \%)$. This increment is well under the MMDC of $\pm 80.1 \mathrm{~mm}^{2}$ and does not represent a clinically-significant change in postural steadiness. As depicted in Figure 5, COP speed values were reduced during all conditions after the exercise intervention in both the antero-posterior $(\mathrm{A} / \mathrm{P})$ and $\mathrm{M} / \mathrm{L}$ directions. In the $\mathrm{A} / \mathrm{P}$ direction, the decrease in COP speed ranged from $44.1 \%$ (EO, firm surface) to $79.1 \%$ (EO, foam surface, $\mathrm{LLF}$ ). In the $\mathrm{M} / \mathrm{L}$ direction, the diminution in COP speed ranged from $50.5 \%$ (EO, firm surface) to $72.0 \%$ (EO, foam surface, LLF). During condition 1 (EO, firm surface),
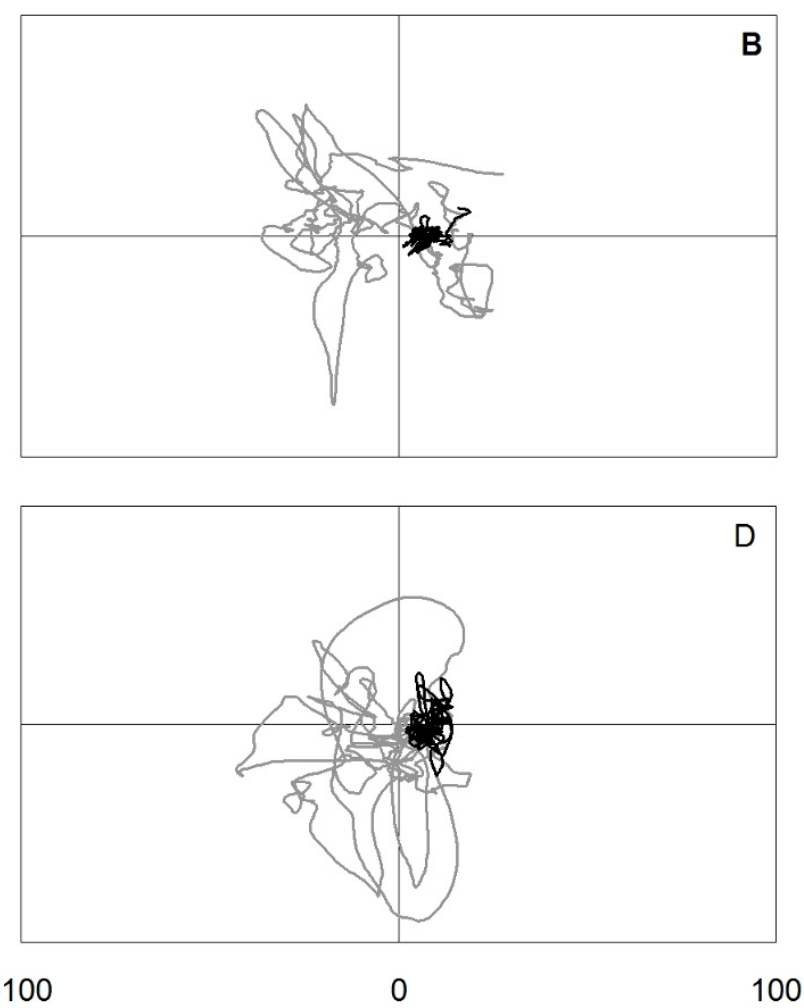

Figure 4

Statokinesigrams (sway area) during eyes-closed conditions on a soft surface with different head positions: (A) head neutral; (B) left lateral flexion; (C) right lateral flexion; (D) extension. (grey line): pre-intervention COP displacement; (black line): post-intervention COP displacement. 

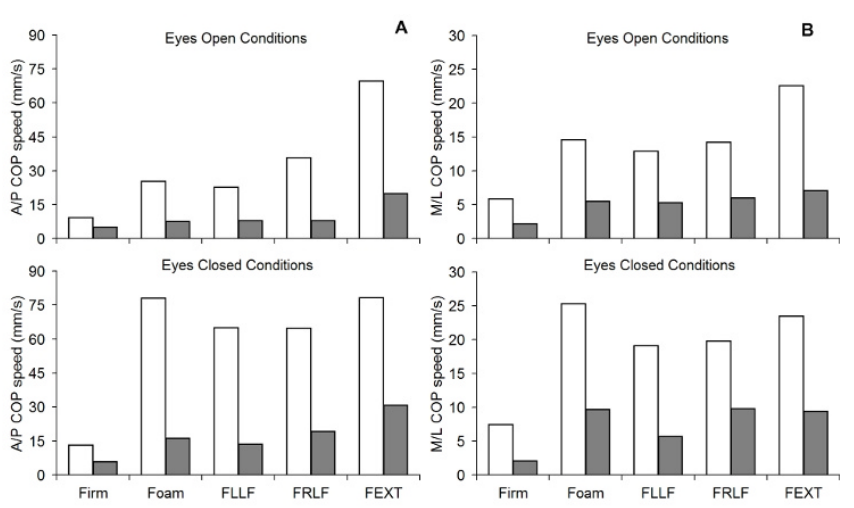

Figure 5

Mean COP speed $(\mathrm{mm} / \mathrm{s})$ data during $\mathrm{mCTSIB}$ conditions before (blank) and after (black) the intervention in (A) the antero-posterior (A/P) and (B) mediolateral $(\mathbf{M} / \mathbf{L})$ directions. Firm = Firm support surface; Foam $=$ Foam support surface; FLLF = Foam support surface with left lateral flexion; FRLF = Foam support surface with right lateral flexion; FEXT = Foam support surface with neck extension

the decline in COP speed represented a clinically-significant change in postural steadiness with $-4.1 \mathrm{~mm} / \mathrm{s}$ and $3.7 \mathrm{~mm} / \mathrm{s}$ in the $\mathrm{A} / \mathrm{P}$ and $\mathrm{M} / \mathrm{L}$ directions, respectively.

\section{Discussion}

The patient demonstrated postural unsteadiness hypothesized to be a consequence of traumatic CNP. Pre-intervention evaluation revealed that her postural control system was challenged when postural control sensory inputs were altered, particularly during the head-extended-backward condition. Compared to normative values, the COP data were well above those obtained in healthy adults.

To improve postural steadiness, we chose to use an intervention emphasizing strengthening and sensorimotor exercises combined with spinal manipulative therapy. Post-intervention COP measures indicated a drastic reduction in postural sway during trials with changes in neck orientation. Indeed, a greater decrease in postural sway was observed (in the range of $90-95 \%$ of the initial assessment) during balance conditions when sensory inputs were altered. For neutral head position conditions, post-intervention COP measures were close to the reference values obtained in young, healthy subjects in the same laboratory setting according to identical algorithm calculations (Table 2).

Although the patient's postural steadiness improved, the information regarding clinical outcomes evolution is limited. One limitation of this case study was that neck pain was not systematically assessed during the intervention program. The patient reported a decrease in neck pain on the VAS from 6 to 2 post-intervention. She also disclosed a significant reduction in neck and upper trunk stiffness in the morning. Pain intensity is often considered as an outcome measure in therapeutic intervention studies. Nevertheless, the subjective rating of pain intensity in such investigations could be influenced by fluctuations in and the intermittent nature of neck pain. Several authors did not find a relationship between pain intensity and cervical kinesthetic sense [33-36]. However, Lee et al. [35] showed that pain frequency, not pain intensity, was associated with impairment of cervical kinesthetic sense. Further intervention and follow-up studies are needed to examine the relationship between the decline in pain intensity and frequency and the improvement in cervical kinesthetic sense, cervical function and postural steadiness.

Another limitation was that impairment of kinesthetic sense or sensorimotor control of the cervical spine (joint position error) was not assessed prior to and after the intervention program, and neither was oculomotor control. It is thus impossible to link the improvement of postural control to increased sensorimotor control of the cervical spine and oculomotor control. Previous work showed that proprioceptive exercises, similar to those prescribed in this study, enhance kinesthesia and position sense of the cervical spine in CNP subjects $[25,37]$. On the other hand, improvement in muscle force/endurance may have been responsible for the changes observed in postural stability [22].

Disability and quality of life questionnaires [38] are recommended in the assessment of CNP patients and could

Table 2: Mean and standard deviation (mean \pm SD) of centre of pressure (COP) variables calculated across 4 sensory conditions.

\begin{tabular}{|c|c|c|c|c|c|}
\hline \multirow[b]{2}{*}{ COP variables } & \multirow[b]{2}{*}{ Direction } & \multicolumn{4}{|c|}{ mCTSIB } \\
\hline & & Condition I & Condition 2 & Condition 6 & Condition 7 \\
\hline \multirow[t]{2}{*}{ COP speed $(\mathrm{mm} / \mathrm{s})$} & $\mathrm{A} / \mathrm{P}$ & $7.6(1.5)$ & $10.8(2.5)$ & $9.9(2.8)$ & $10.6(2.1)$ \\
\hline & $M / L$ & $4.4(1.2)$ & $6.2(2.2)$ & $5.3(1.7)$ & $5.6(1.7)$ \\
\hline COP sway area $\left(\mathrm{mm}^{2}\right)$ & -- & $181.4(91.9)$ & $261.1(98.7)$ & $187.2(110.3)$ & $220.2(79.8)$ \\
\hline
\end{tabular}

Data were gathered from 30 subjects (age: $23.7 \pm 3.8$ years; weight: $66.3 \pm 14.8 \mathrm{~kg}$; height: $170.3 \pm 11.8 \mathrm{~cm}$ )

Abbreviations: $\mathrm{COP}=$ centre of pressure; $\mathrm{A} / \mathrm{P}=$ antero-posterior; $\mathrm{M} / \mathrm{L}=$ medio-lateral. 
have been used in this particular case. Finally, the lack of follow-up assessments, owing to the fact that the patient was returned to work by her physician, should also be considered as a limitation of the present study.

\section{Conclusion}

This case report indicates that an 8-week rehabilitation program combining therapeutic exercises with spinal manipulative therapy may have had an effect on improvement of postural control in a trauma CNP patient with unsteadiness. However, the amelioration of postural steadiness after an intervention program emphasizing strengthening and sensorimotor exercises deserves further investigation. Possible relationships between pain improvement, sensorimotor control of the cervical spine, muscle fitness and postural steadiness need to be explored.

\section{Consent}

Written informed consent was obtained from the patient for publication of this case report and any accompanying images. A copy of the written consent is available for review by the Editor-in-Chief of this journal.

\section{Competing interests}

The authors declare that they have no competing interests.

\section{Authors' contributions}

DL and MD participated in the intervention and writing of the manuscript. DL, AC and RC undertook sensorimotor assessment and data analysis. MD performed all clinical evaluations. All authors have read and concur with the final manuscript. They also accept responsibility for its contents. The article has not been submitted or published elsewhere.

\section{Acknowledgements}

This work was supported in part by the Fonds Institutionnel de la recherche-UQTR (307I08I) and the Quebec Chiropractic Research Foundation. The authors thank Pierre Black for editing the figures.

\section{References}

I. Côté P, Cassidy JD, Carroll L: The factors associated with neck pain and its related disability in the Saskatchewan population. Spine 2000, 25(9): I 109-III7.

2. Fejer R, Kyvik KO, Hartvigsen J: The prevalence of neck pain in the world population: a systematic critical review of the literature. Eur Spine J 2006, I5(6):834-848.

3. Rubin AM, Woolley SM, Dailey VM, Goebel JA: Postural stability following mild head or whiplash injuries. Am J Otol 1995, I6(2):216-221.

4. Karlberg M, Persson L, Magnusson M: Impaired postural control in patients with cervico-brachial pain. Acta Otolaryngol 1995, I I 5(S520):440-442.

5. Treleaven J, Jull G, Lowchoy N: Standing balance in persistent whiplash: a comparison between subjects with and without dizziness. J Rehabil Med 2005, 37(4):224-229.

6. Field S, Treleaven J, Jull G: Standing balance: a comparison between idiopathic and whiplash-induced neck pain. Man Ther 2008, 13(3): |83-19|.
7. Courtine G, Papaxanthis C, Laroche D, Pozzo T: Gait-dependent integration of neck muscle afferent input. Neuroreport 2003, I4(18):2365-2368.

8. Jackson RT, Epstein CM: Effect of head extension on equilibrium in normal subjects. Ann Otol Rhinol Laryngol 199I, 100(1):63-67.

9. Kogler A, Lindfors J, Odkvist LM, Ledin T: Postural stability using different neck positions in normal subjects and patients with neck trauma. Acta Otolaryngol 2000, I 20(2): $15|-| 55$.

10. Alund M, Ledin T, Odkvist L, Larsson SE: Dynamic posturography among patients with common neck disorders. A study of 15 cases with suspected cervical vertigo. J Vestib Res 1993, 3(4):383-389.

II. Anastasopoulos D, Mergner T: Canal-neck interaction in vestibular nuclear neurons of the cat. Exp Brain Res 1982, 46(2):269-280.

12. Wilson VJ, Yamagata Y, Yates BJ, Schor RH, Nonaka S: Response of vestibular neurons to head rotations in vertical planes. III. Response of vestibulocollic neurons to vestibular and neck stimulation. J Neurophysiol 1990, 64(6): 1695-1703.

13. Treleaven J: Sensorimotor disturbances in neck disorders affecting postural stability, head and eye movement control - Part 2: Case studies. Man Ther 2008, 13:266-275.

14. Treleaven J, Jull G, Sterling M: Dizziness and unsteadiness following whiplash injury: characteristic features and relationship with cervical joint position error. J Rehabil Med 2003, 35(I):36-43.

15. Treleaven J, LowChoy N, Darnell R, Panizza B, Brown-Rothwell D, Jull $\mathrm{G}$ : Comparison of sensorimotor disturbance between subjects with persistent whiplash-associated disorder and subjects with vestibular pathology associated with acoustic neuroma. Arch Phys Med Rehabil 2008, 89(3):522-530.

16. Le Pera D, Graven-Nielsen T, Valeriani M, Oliviero A, Di Lazzaro V, Tonali PA, Arendt-Nielsen L: Inhibition of motor system excitability at cortical and spinal level by tonic muscle pain. Clin Neurophysiol 200I, I I2(9):1633-164I.

17. Flor $\mathrm{H}$ : Cortical reorganisation and chronic pain: implications for rehabilitation. J Rehabil Med 2003:66-72.

18. Capra NF, Ro JY: Experimental muscle pain produces central modulation of proprioceptive signals arising from jaw muscle spindles. Pain 2000, 86(I-2): $151-162$.

19. Gdowski GT, McCrea RA: Neck proprioceptive inputs to primate vestibular nucleus neurons. Exp Brain Res 2000, I35(4):5 I I-526.

20. Armstrong BS, McNair P, Taylor D: Head and neck position sense. Sports Med 2008, 38(2): $101-117$.

21. McPartland JM, Brodeur RR, Hallgren RC: Chronic neck pain, standing balance, and suboccipital muscle atrophy - a pilot study. J Manipulative Physiol Ther 1997, 20(I):24-29.

22. Vuillerme N, Pinsault N, Vaillant J: Postural control during quiet standing following cervical muscular fatigue: effects of changes in sensory inputs. Neurosci Lett 2005, 378: I35-139.

23. Kay TM, Gross A, Goldsmith C, Santaguida PL, Hoving J, Bronfort G: Exercises for mechanical neck disorders. The Cochrane Database of Systematic Reviews 2005, 3:.

24. Verhagen A, Scholten-Peeters G, de Bie R, Bierma-Zeinstra S: Conservative treatments for whiplash (Review). Cochrane Database Syst $\operatorname{Rev} 2005, \mathrm{I}:$.

25. Jull G, Falla D, Treleaven J, Hodges P, Vicenzino B: Retraining cervical joint position sense: the effect of two exercises regimes. J Orthop Res 2007, 25(3):404-4I 2.

26. Treleaven J: Sensorimotor disturbances in neck disorders affecting postural stability, head and eye movement control. Man Ther 2008, I3(1):2-1I.

27. Hurwitz EL, Carragee EJ, Velde G van der, Carroll L, Nordin M, Guzman J, Peloso PM, Holm LW, Cote P, Hogg-Johnson S, Cassidy JD, Haldeman S: Treatment of neck pain: noninvasive interventions: Results of the Bone and Joint Decade 2000-20 10 Task Force on Neck Pain and Its Associated Disorders. Spine 2008, 33(4):SI 23-SI52.

28. Bronfort G, Evans R, Nelson B, Aker PD, Goldsmith CH, Vernon H: $A$ randomized clinical trial of exercise and spinal manipulation for patients with chronic neck pain. Spine 200I, 26(7):788-797. discussion 798-799

29. Evans R, Bronfort G, Nelson B, Goldsmith CH: Two-year follow-up of a randomized clinical trial of spinal manipulation and two 
types of exercise for patients with chronic neck pain. Spine 2002, 27(21):2383-2389.

30. Doyle TL, Newton RU, Burnett AF: Reliability of traditional and fractal dimension measures of quiet stance center of pressure in young, healthy people. Arch Phys Med Rehabil 2005, 86(10):2034-2040.

31. Lafond D, Duarte M, Prince F: Comparison of three methods to estimate the center of mass during balance assessment. J Biomech 2004, 37(9): | 42|- | 426.

32. Lafond D, Corriveau H, Hébert R, Prince F: Intrasession reliability of center of pressure measures of postural steadiness in healthy elderly people. Arch Phys Med Rehabil 2004, 85(6):896-90I.

33. Armstrong BS, Peter JM, Maynard W: Head and neck position sense in whiplash patients and healthy individuals and the effect of the cranio-cervical flexion action. Clin Biomech 2005, 20:675-684.

34. Heikkila HV, Wenngren B: Cervicocephalic kinesthetic sensibility, active range of cervical motion, and oculomotor function in patients with whiplash injury. Arch Phys Med Rehabil 1998, 79(9): 1089-1094

35. Lee $\mathrm{H}$, Teng $\mathrm{C}$, Chai $\mathrm{H}$, Wang S: Test-retest reliability of cervicocephalic kinesthetic sensibility in three cardinal planes. Man Ther 2006, I I(I):6I-68.

36. Rix GD, Bagust J: Cervicocephalic kinesthetic sensibility in patients with chronic, nontraumatic cervical spine pain. Arch Phys Med Rehabil 200I, 82(7):9II-919.

37. Revel M, Minguet M, Gregoy P, Vaillant J, Manuel JL: Changes in cervicocephalic kinesthesia after a proprioceptive rehabilitation program in patients with neck pain: a randomized controlled study. Arch Phys Med Rehabil 1994, 75(8):895-899.

38. Nordin M, Carragee EJ, Hogg-Johnson S, Weiner SS, Hurwitz EL Peloso PM, Guzman J, Velde G Van der, Carroll LJ, Holm LW, Côté $\mathrm{P}$, Cassidy JD, Haldeman S: Assessment of neck pain and its associated disorders: Results of the Bone and Joint Decade 20002010 Task Force on Neck Pain and Its Associated Disorders. Eur Spine J 2008, I7(suppI I):SIOI-SI 22.

Publish with Bio Med Central and every scientist can read your work free of charge

"BioMed Central will be the most significant development for disseminating the results of biomedical research in our lifetime. "

Sir Paul Nurse, Cancer Research UK

Your research papers will be:

- available free of charge to the entire biomedical community

- peer reviewed and published immediately upon acceptance

- cited in PubMed and archived on PubMed Central

- yours - you keep the copyright 